\title{
ESTUDO DE VIABILIDADE DO USO DA ENZIMA CATALASE, DEPOSITADA EM SUPERFÍCIE DE CARBONO JUNTO COM LÍQUIDO IÔNICO PRÓTICO, PARA A CONSTRUÇÃO DE UM BIOLETRODO
}

\author{
G. ROSALES M ${ }^{1}$, E. JARDIM ${ }^{1}$, V. C. FERNANDES ${ }^{2}$, S. MATTEDI $^{1}$, A. ROSÁRIO ${ }^{2}$ e J. S. \\ BOAVENTURA $^{1}$ \\ ${ }^{1}$ Universidade Federal da Bahia, Departamento de Engenharia Química Escola Politécnica \\ ${ }^{2}$ Universidade Federal da Bahia, Departamento de Química \\ E-mail para contato: grosalesmtoo@gmail.com
}

\begin{abstract}
RESUMO - A catalase, enzima capaz de oxidar o etanol seguindo um mecanismo peroxidático, foi imobilizada por uma combinação entre às técnicas "layer by layer" (LBL) e eletrodeposição para a construção de um bioeletrodo, alternando com camadas de líquido iônico prótico (propionato de $\mathrm{N}$-metil-2-hidroxietilamina). O bioeletrodo resultante foi avaliado frente aos substratos peróxido de hidrogênio e etanol por voltametria cíclica e Espectroscopia Eletrônica de Impedância (EIS), encontrando-se que a resistividade diminuiu a cada adição de camada eletroativa e a resistência geral do eletrodo também diminuiu com a deposição de catalase. A superfície foi avaliada por Microscopia Eletrônica de Varredura e por Espectrometria de Infravermelho por transformada de Fourier, confirmando a modificação da mesma e a presença de possíveis ligações covalentes. Assim, com os resultados obtidos pode se assegurar que a catalase é uma enzima factível de usar na construção de um bioeletrodo e que o líquido iônico confere propriedades condutoras aos materiais.
\end{abstract}

\section{INTRODUÇÃO}

A catalase, ou mais exatamente hidroperoxidase, classificada pela IUPAC como 1.11.1.6 (Sober, 1970) é uma enzima da classe das oxirredutases. Possui uma estrutura tetramérica e é composta por quatro subunidades idênticas ligadas cada uma a um grupo hematina ou heme. Cada subunidade possui no seu sítio ativo um íon $\mathrm{Fe}^{3+}$ situado dentro da estrutura da enzima.

A catalase, considerada uma enzima ubíqua presente principalmente nas peroxissomas, faz parte do sistema de proteção da célula contra a oxidação devida à formação de radicais livres, produtos de 
reações secundárias do oxigênio. A catalase decompõe o peróxido de hidrogênio formado no interior da célula pela enzima superóxido dismutase (Eq.1), liberando água e oxigênio como produtos finais (Eq. 2). (Kimbrough et. al. 1997) Isto é definido como atividade catalática. (Lente e Pepoy, 1990)

$$
\begin{aligned}
& 2 \mathrm{O}_{2}^{-}+2 \mathrm{H}^{+} \stackrel{\text { superóxidodismutase }}{\longrightarrow} \mathrm{H}_{2} \mathrm{O}_{2}+\mathrm{O}_{2} \\
& 2 \mathrm{H}_{2} \mathrm{O}_{2} \stackrel{\text { catalase }}{\longrightarrow} 2 \mathrm{H}_{2} \mathrm{O}+\mathrm{O}_{2}
\end{aligned}
$$

Outros estudos referem que quando há a presença de substancias tóxicas dentro do organismo, como o etanol (em geral doadores de prótons), a catalase oxida entre 2-3\% desta espécie protegendo a célula da intoxicação na presença de concentrações relativamente baixas de $\mathrm{H}_{2} \mathrm{O}_{2}$. Isto é definido como atividade peroxidática. [(Jordão Jr, 1988) (Mehler, 1957)]

$$
\mathrm{CH}_{3} \mathrm{CH}_{2} \mathrm{OH}+\mathrm{H}_{2} \mathrm{O}_{2} \stackrel{\text { catalase }}{\longrightarrow} \mathrm{CH}_{3} \mathrm{CHO}+2 \mathrm{H}_{2} \mathrm{O}
$$

Dependendo das concentrações de $\mathrm{H}_{2} \mathrm{O}_{2}$ e etanol, a catalase pode reagir via peroxidática ou catalática, sendo que esta última ocorre a uma velocidade 4 a 5 vezes mais rápida que a primeira. Lente e Pepoy, (1990) estabeleceram uma relação molar de trabalho de peróxido de hidrogênio a etanol muito menor a 0,067 a fim de assegurar que a reação ocorra efetivamente de forma peroxidática.

A aplicação da catalase como um catalisador capaz de oxidar o etanol poderia solucionar o problema atual das células a combustível de etanol (DAFC, Direct Alcohol Fuel Cell), onde os catalisadores como platina simples ou suportada em diferentes metais nobres, como o ródio e o ósmio, têm pobre desempenho, devido à formação de intermediários na reação de oxidação do etanol, os quais bloqueiam os sítios ativos do catalisador e geram perdas no desempenho da célula. (Oliveira Neto et al. 2006)

Poucas publicações encontram-se na literatura onde se utiliza a catalase diretamente para oxidar o etanol, como é o caso do trabalho de Akyilmaz e Dinçkaya, (2003), que desenvolveram um biosensor baseado na catalase imobilizada para a determinação de etanol em bebidas. Campanella et al. (2010) também desenvolveram um biosensor para determinar concentrações de etanol em gasolinas livres de chumbo. Os dois trabalhos correlacionam a resposta da enzima com a produção de $\mathrm{O}_{2}$, medido por um eletrodo amperométrico tipo Clark. Hnaien et al. (2010) construíram um biosensor bi-enzimatico composto por álcool oxidase (AOX) e catalase (CAT) no qual a AOX oxida o etanol, produzindo peróxido de hidrogênio e acetaldeído, e a CAT aproveita o peróxido e por sua vez também oxida o etanol a acetaldeído e água. Rosales et al. (2008) construíram um eletrodo a base de catalase imobilizada pelo método CLEA misturada com grafite e suportada num eletrodo de carbono vítreo, determinando por voltametria cíclica os picos de oxidação e redução da enzima. Rosales (2014) encontrou que a resistência de um eletrodo de carvão ativado diminui com a adição de catalase imobilizada através de análise por EIS.

Devido a dificuldades da catalase para retirar seus elétrons do seu sítio ativo e transporta-los à 


\section{9 a 22 de outubro de 2014 \\ Florianópolis/SC}

superfície metálica do bioeletrodo, se faz necessária a aplicação de substâncias que aprimorem a capacidade condutora do biocatalisador. Nesse sentido os líquidos iônicos, graças a suas propriedades de alta condutividade iônica, baixa volatilidade e não inflamabilidade, são interessantes para serem aplicadas em combinações com a enzima e diversos metais condutores. (Sun e Armstrong, 2010).Vasta literatura (incluindo livros e artigos) tem sido publicada onde se descreve o uso dos líquidos iônicos nessa área, seja como eletrólito para novos eletrodos de referência ou em células a combustível, e também como solvente de biomoléculas para serem analisadas por técnicas eletroquímicas. (Ohno, 2005)

Os biosensores eletroquímicos baseados em líquidos iônicos têm sido reportados pela sua contribuição na melhora da transferência eletrônica direta de várias enzimas redox (Saadati et al. 2012). Neste trabalho foram usadas as técnicas de deposição eletroquímica e LBL (Layer by Layer) para imobilizar a catalase junto com o líquido iônico prótico, propionato de N-metil-2hidroxietilamina (sintetizado por Álvarez et al., (2010)), sobre uma superfície de titânio recoberto por casting com carvão ativado. A combinação destas técnicas envolve uma adsorção alternada da enzima e o eletrólito (líquido iônico) desde a solução para a superfície do eletrodo através de adsorção eletrostática e formação de ligações covalentes. A modificação da superfície foi avaliada eletroquimicamente pelas técnicas de voltametria cíclica e Espectroscopia Eletrônica de Impedância (EIS) e estruturalmente pelas técnicas de Infravermelho com transformada de Fourier (FT-IR) e por Microscopia Eletrônica de Varredura (MEV).

\section{METODOLOGIA}

\subsection{Eletrodos Suportados em Substrato de Titânio}

Os eletrodos foram construídos sobre uma peça de titânio com área geométrica de $1 \mathrm{~cm}^{2}$. Uma tinta composta de $5 \mathrm{mg}$ de carvão ativado foi elaborada adicionando-se inicialmente $150 \mu \mathrm{L}$ de Nafion ${ }^{\circledR}$ e $50 \mu \mathrm{L}$ de álcool isopropílico. Esta composição foi misturada até evaporar todo o solvente e, após posteriores adições de algumas gotas de álcool isopropílico ( 2 a 3 por vez, a depender da quantidade de sólido), a tinta foi colocada por "casting" sob o substrato de titânio.

\subsection{Eletrodeposição de Catalase e Propionato de N-Metil-2-Hidroxietilamina}

O sistema eletroquímico foi prata 1000 como eletrodo de referência (ER), eletrodo de titânio pintado com carvão ativado como eletrodo de trabalho (EW) e fio de platina como contraeletrodo (EC), imersos em $40 \mathrm{~mL}$ de tampão fosfato $50 \mathrm{mM} \mathrm{pH} \mathrm{7,0.} \mathrm{O} \mathrm{procedimento} \mathrm{da} \mathrm{eletrodeposição} \mathrm{é} \mathrm{uma}$ modificação de Saadati et al., (2012) e consistiu em 3 passos: 1) Aplicação de 15 ciclos de potencial do eletrodo imerso numa solução do líquido iônico de concentração de $10 \mathrm{mM}$, numa janela de 0 a 2,0 V e uma velocidade de varredura de $100 \mathrm{mV} / \mathrm{s}$. 2) Imersão do eletrodo numa solução de catalase de 4 $\mathrm{mg} / \mathrm{mL}$ e a aplicação de 15 ciclos numa janela de potencial de $-0,7$ a $0,7 \mathrm{~V}$. 3) Imersão do eletrodo no líquido iônico puro durante 5 minutos para favorecer as interações eletrostáticas entre o líquido com 
carga positiva e a enzima com carga negativa. Depois dos 5 minutos o eletrodo foi lavado em tampão fosfato, para eliminar o excesso de líquido iônico, e mergulhado novamente na solução de catalase para repetir o passo 2. O procedimento de deposição entre os passos 2 e 3 é feito por 7 vezes mais.

\subsection{Análise por Espectroscopia Eletrônica de Impedância}

Todas as medidas de EIS foram feitas em potenciostato Metrohm, Autolab PGSTAT128N com módulo FRA32M, utilizando o software NOVA versão 1.10.2. As medidas foram feitas em modo potenciostático, com um potencial fixo de $-0,15 \mathrm{~V}$, para o branco e o eletrodo modificado numa solução tampão $50 \mathrm{mM}$ e pH 7,0 (Sol 1). Também foi testada a resposta do eletrodo modificado na solução de $\mathrm{H}_{2} \mathrm{O}_{2}$ 4,0 mmol/L ( $\mathrm{Sol} 2$ ) e solução de $\mathrm{H}_{2} \mathrm{O}_{2}$ 4,0 mmol/L e etanol 0,26 mol/L (Sol 3).

\subsection{Avaliação estrutural do eletrodo modificado}

As análises de MEV foram feitas em um microscópio Jeol, JSM-6610, com aumento de 100.000. O eletrodo modificado e seu branco foram sometidos previamente a um banho de ouro. As análises de FT-IR foram feitas em espectrômetro Shimadzu, PRESTIGE-21, usando o acessório ATR da PIKE Technologies. Todas as análise foram feitas na faixa de $600 \mathrm{a} 4400 \mathrm{~cm}^{-1}$.

\section{RESULTADOS E DISCUSSÃO}

As voltametrias cíclicas indicam uma mudança na superfície do eletrodo, observadas como uma diminuição geral na resistividade e também na densidade de corrente. A Figura 1A mostra o branco antes da eletrodeposição e foi realizado numa janela de potencial de 0,0 a 2,0 $\mathrm{V}$ e velocidade de varredura de $100 \mathrm{mV} / \mathrm{s}$. Observa-se comportamento resistivo indicado pela inclinação da curva, porém com a forma da resposta de carvão ativado. Na Figura 1B tem-se as voltametrias dos oito passos de ciclagem; a largura da curva informa a densidade de corrente, a qual diminui com o aumento da eletrodeposição. Do mesmo jeito, a inclinação da curva indica quão resistivo é o material; a cada etapa de eletrodeposição observou-se também que a curva, apesar de diminuir sua densidade de corrente, ficou menos inclinado, ou seja, a resistividade do material diminuiu.
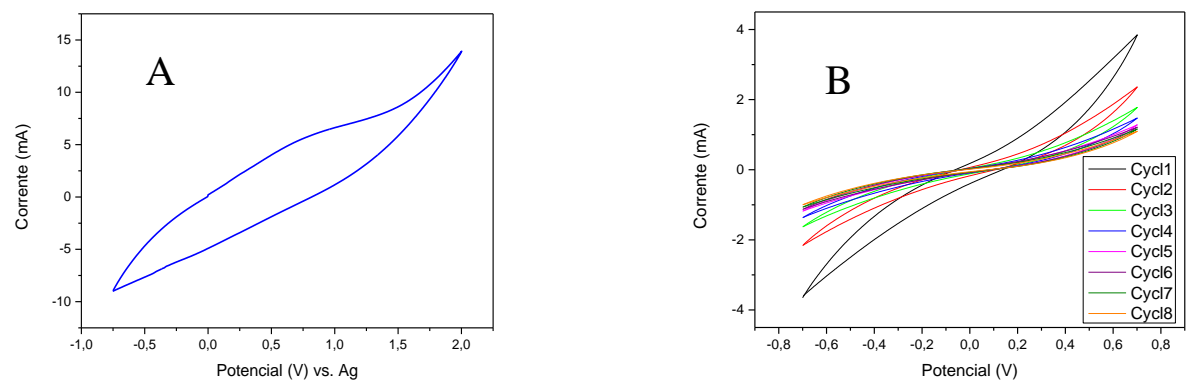

Figura 1. A. Voltametria cíclica do branco de eletrodeposição em tampão fosfato $50 \mathrm{mM} \mathrm{pH} \mathrm{7,0.} \mathrm{B.} \mathrm{Voltametrias}$ cíclicas das 8 etapas de eletrodeposição em solução de catalase $4 \mathrm{mg} / \mathrm{mL}$ 
A densidade de corrente inicial corresponde a processos capacitivos, ou seja, à formação de dupla camada elétrica entre o carvão e o eletrólito; a diminuição da densidade indica que a superfície vai se cobrindo com o líquido iônico e a catalase. A resistividade diminui (a condutividade do material aumentou ao longo da eletrodeposição) porque foram inseridas na superfície substâncias mais condutoras do que o carvão ativado.

As curvas de EIS indicam também que a superfície foi modificada eletroquimicamente, pois o tamanho do semicírculo variou. Na Figura 2A observa-se um pequeno semicírculo a altas frequências que depois da eletrodeposição se vê grandemente aumentado, como mostrado em B. Estes semicírculos correspondem a fenômenos próprios da interface eletrodo-eletrólito, na qual podem acontecer processos faradáicos e não faradáicos. A altas frequências, à esquerda do gráfico, o intercepto em Z indica a resistência da solução; e a frequências intermediarias complementando o semicírculo, se define a resistência de polarização, igualmente com intercepto em $Z$.

A linha reta no gráfico de Nyquist (Figura 2) representa um efeito difusivo que afeta os fenômenos que acontecem na interface eletrodo - eletrólito; inclinação diferente de $45^{\circ}$ pode-se dizer que é devida a um elemento de fase constante (CPE).
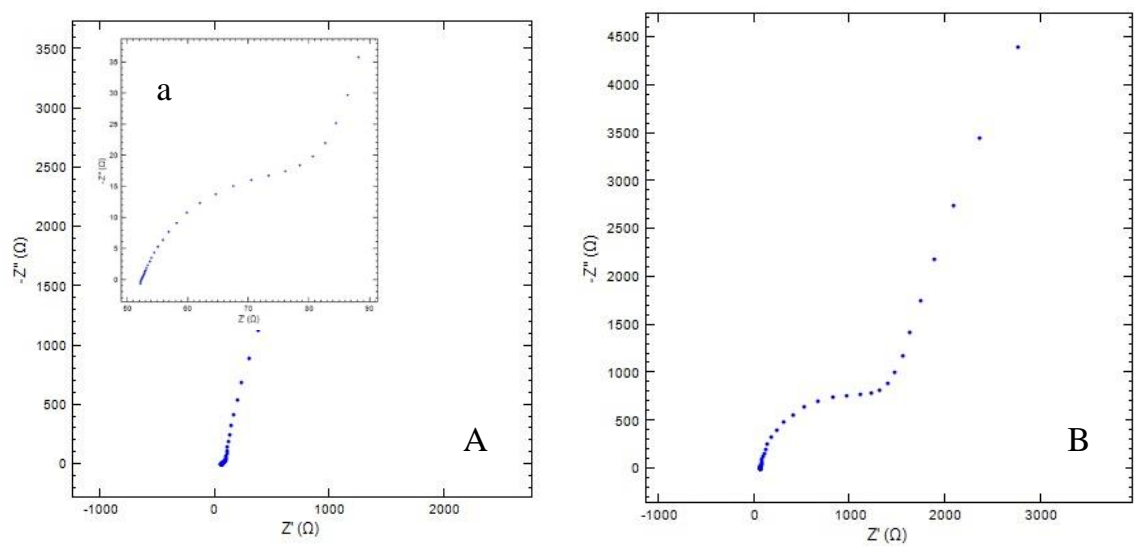

Figura 2. A. Nyquist do branco da eletrodeposição. a. Inset: Ampliação do semicírculo a altas frequências. B. Nyquist do eletrodo após a modificação.

Quando o eletrodo modificado foi submetido às soluções 2 e 3, os efeitos pela difusão na forma de um CPE desapareceram o qual se observa nos gráficos de Nyquist apresentados na Figura 3. 

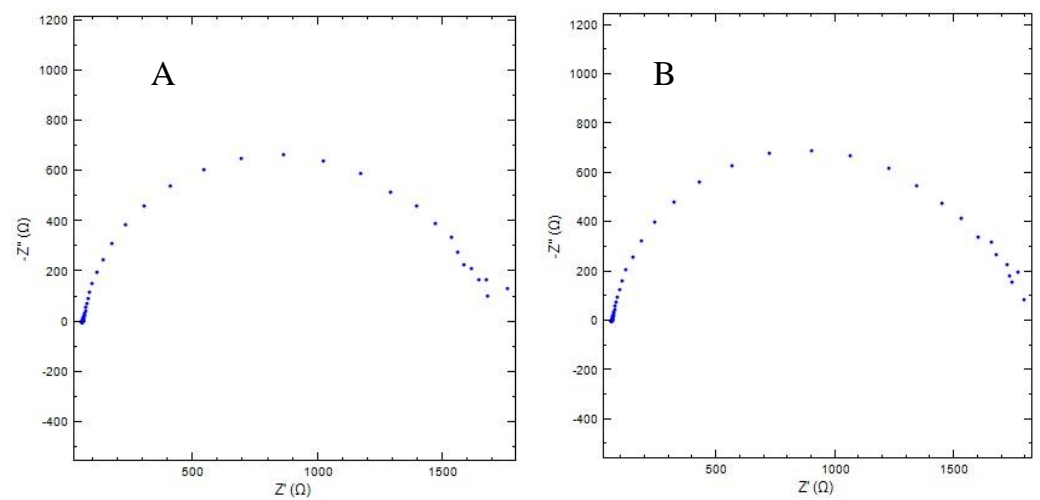

Figura 3. Nyquist da resposta do eletrodo modificado frente a: A. Sol 2, B. Sol 3.

Para compreender melhor a contribuição da eletrodeposição se calcularam os parâmetros eletroquímicos obtidos em cada gráfico de Nyquist e se apresentam na Tabela 1.

Tabela 1 - Parâmetros eletroquímicos calculados pelo programa NOVA.

\begin{tabular}{|c|r|r|r|r|}
\hline & \multicolumn{1}{|c|}{ Branco } & \multicolumn{1}{c|}{ Sol 1 } & \multicolumn{1}{c|}{ Sol 2 } & \multicolumn{1}{c|}{ Sol 3 } \\
\hline CPE (F) & $3,08 \mathrm{E}-05$ & $3,01 \mathrm{E}-05$ & $2,51 \mathrm{E}-05$ & $2,40 \mathrm{E}-05$ \\
\hline $\mathbf{R p}(\boldsymbol{\Omega})$ & 49,26 & 1904,80 & 1652,10 & 1755,80 \\
\hline $\mathbf{R s}(\boldsymbol{\Omega})$ & 52,31 & 50,18 & 46,01 & 45,49 \\
\hline $\begin{array}{c}\hat{\text { Angulo da }} \\
\text { reta }\end{array}$ & $71^{\circ}$ & $71^{\circ}$ & ------- & ------ \\
\hline
\end{tabular}

Rp: Resistência de polarização. Rs: Resistência da solução

$\mathrm{O}$ valor do CPE correspondente à capacitância se mantém praticamente inalterado depois da deposição, mas na presença de espécies eletroativas (Sol 2 e Sol 3) este valor diminui. Este comportamento é similar para a resistência da solução, mas a resistência de polarização aumenta significativamente após a eletrodeposição como discutido anteriormente.

Nas imagens do MEV mostradas na Figura 4, pode-se observar que a superfície do eletrodo de carbono foi modificada. A superfície do carbono, inicialmente lisa (Figura 4A), foi recoberta e apresenta glomérulos com cavidades arredondadas, possivelmente próprios da catalase (Figura 4B).
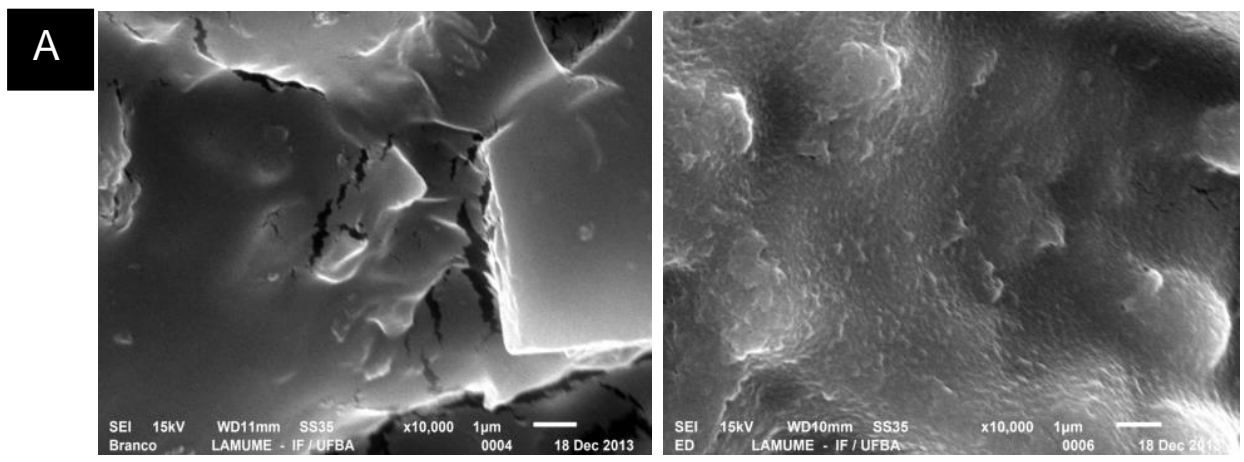

\section{B}

Figura 4 - MEV, em ampliação de 10.000 vezes, para: A. branco do eletrodo e B. eletrodo modificado. 
Os resultados do FTIR, mostrados na Figura 5, confirmam também que houve modificação na superfície do eletrodo. A banda em $1200 \mathrm{~cm}^{-1}$ para o branco (em preto) é característica de ligações C$\mathrm{F}$ e corresponde às ligações presentes no Nafion.

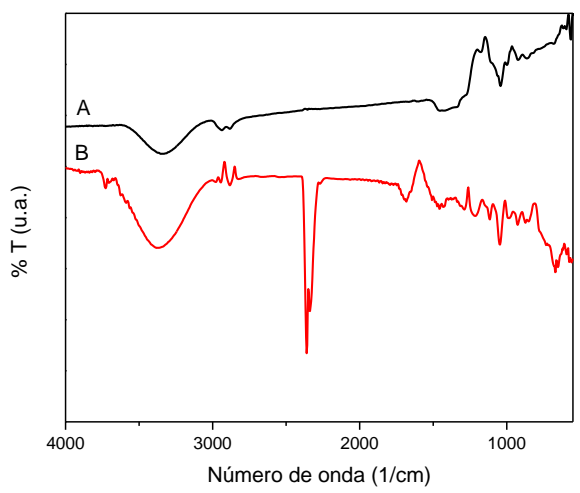

Figura 5 - IR do A para o branco (preto) e B para o eletrodo modificado (vermelho).

Para o espectro do eletrodo modificado (em vermelho) as seguintes bandas foram designadas:

- Em $3750 \mathrm{~cm}^{-1}$ uma banda pequena característica de ligação $\mathrm{O}-\mathrm{H}$ livre, possivelmente da parte catiônica do líquido iônico.

- Em $3300 \mathrm{~cm}^{-1}$ uma banda ampla característica de hidroxila ligada, também do líquido iônico.

- Em $2900 \mathrm{~cm}^{-1}$ duas bandas fracas do estiramento de $\mathrm{C}-\mathrm{H}$.

- Em $2300 \mathrm{~cm}^{-1}$ duas bandas uma mais forte que a outra, a da esquerdo própria de ligação de nitrilos $\mathrm{N} \equiv \mathrm{C}$ e a da lado direita vibrações do $\mathrm{O}-\mathrm{H}$ do ácido carboxílico.

- Em $1700 \mathrm{~cm}^{-1}$ uma banda fraca possivelmente própria de flexão da ligação $\mathrm{N}-\mathrm{H}$ de amina.

- Na região de $1200 \mathrm{~cm}^{-1}$ uma banda da ligação $\mathrm{N}-\mathrm{C}$ pode estar superposta à banda da ligação $\mathrm{F}-\mathrm{C}$ do Nafion®.

Isto confirma que a estrutura foi modificada com a deposição eletroquímica e por LBL e existem evidências de uma ligação covalente entre os aminoácidos da catalase e o ácido carboxílico do líquido iônico, provalvelmente do tipo de base de Schiff, evidenciada pela banda de nitrilas em $2300 \mathrm{~cm}^{-1}$.

Pode-se concluir que a enzima e o líquido iônico foram satisfatoriamente depositados na superfície do carvão. E graças às suas propriedades elétricas, o eletrodo final apresentou uma diminuição na resistividade e com isso um aumento na condutividade. Assim, este processo considera-se uma via interessante para a produção de bioeletrodos a partir da enzima catalase combinada com líquidos iônicos próticos.

O GECIM (Grupo de Energia e Ciência dos Materiais), o GBMAT (Grupo de Pesquisa em Bioinorgânica e Materiais) e o Grupo de Pesquisa em Termodinâmica Aplicada agradecem ao CNPq pelas bolsas de apoio à pesquisa e à FAPEX pelo financiamento do projeto. 


\section{REFERÊNCIAS}

Akyilmaz, E.; Dinçkaya, E. Development of a catalase based biosensor for alcohol determination in beer samples. Talanta, v. 61, p. 113-8, 2003.

Álvarez, V. H.; Dosil, N.; Gonzalez-Cabaleiro, R.; Mattedi, S.; Martin-Pastor, M.; Iglesias, M.; Navaza, J. M. Brønsted Ionic Liquids for Sustainable Processes: Synthesis and Physical Properties. $J$. Chem. Eng. Data, v. 55, p. 625-632, 2010.

Campanella, L.; Capesciotti, G. S.; Gatta, T.; Tomassetti, M. An innovative organic phase enzyme electrode (OPEE) for the determination of ethanol in leadless petrols. Sens. Actuators B, v. 147, p. 78-86, 2010.

Hnaien, M.; Lagarde, F.; Jaffrezic-Renault, N. A rapid and sensitive alcohol oxidase/catalase conductometric biosensor for alcohol determination. Talanta, v. 81, p. 222-7, 2010.

Jordão Jr A. A.; Chiarello P. A.; Bernardes M. S. M.; Vannucchi H. Peroxidação Lipídica e Etanol: Papel da Glutationa Reduzida e da Vitamina E. Medicina, Ribeirão Preto, v. 31, p. 434 - 449, 1998.

Kimbrough, D. R.; Magoun, M. A.; Langfur, M. A Laboratory Experiment Investigating Different Aspects of Catalase Activity in an Inquiry - Based Approach. J. Chem. Edu., v. 74(2), p. 210, 1997.

Lente, F. Van; Pepoy, M. Coupled-Enzyme Determination of Catalase Activity in Erythrocytes. Clinical Chemistry, v. 36(7), p. 1339-1343, 1990.

Mehler. Introduction to enzymology. Nova Iorque: Academic Press INC, 1957.

Neto, A. O.; Dias, R. R.; Ribeiro, V. A.; Spinacé, E. V.; Linardi, M. Eletro-oxidação de etanol sobre eletrocatalisadores $\mathrm{PtRh} / \mathrm{C}, \mathrm{PtSn} / \mathrm{C}$ e $\mathrm{PtSnRh} / \mathrm{C}$ preparados pelo método da redução por álcool. Eclética Química, v. 31(1), p. 81-88, 2006.

Ohno, H. Electrochemical aspects of ionic liquids. Koganei, Ed. John Wiley \& Sons, Inc., 2005.

Rosales, G. Estudo da viabilidade da enzima Catalase imobilizada numa matriz de entrecruzamento (CLEA) para ser empregada como bioeletrodo. Dissertação M. Sc. Universidade Federal da Bahia, 2014.

Rosales, G., Fiúza, C. R. P., Silva, M. A., Tanaka, A. A., Mattedi, S.; José, N. M., \& Boaventura, J. S. Imobilizaçao da catalase pelo método CLEA para a construçao de bioeletrodo para PEMFC. XVII Congresso Brasileiro de Engenharia Química, 2008.

Saadati, S.; Salimi, A.; Hallaj, R.; Rostami, A. Layer by layer assembly of catalase and amineterminated ionic liquid onto titanium nitride nanoparticles modified glassy carbon electrode: study of direct voltammetry and bioelectrocatalytic activity. Anal. Chim. Acta, v. 753, p. 32-41, 2012.

Sober, H. A. Handbook of biochemistry, Selected data for molecular biology ( $2^{\mathrm{a}}$ ed.). Cleveland: CRC Press, 1970.

Sun, P.; Armstrong, D. W. (2010). Ionic liquids in analytical chemistry. Anal. Chim. Acta, v. 661(1), p. 1-16, 2010. 